\title{
Estimating institutional physician turnover attributable to self-reported burnout and associated financial burden: a case study
}

Maryam S. Hamidi ${ }^{1,2}$, Bryan Bohman ${ }^{2,3}$, Christy Sandborg ${ }^{4}$, Rebecca Smith-Coggins ${ }^{5}$, Patty de Vries ${ }^{2}$, Marisa S. Albert ${ }^{6}$, Mary Lou Murphy ${ }^{2}$, Dana Welle ${ }^{7}$ and Mickey T. Trockel ${ }^{1,2^{*}}$

\begin{abstract}
Background: Awareness of the economic cost of physician attrition due to burnout in academic medical centers may help motivate organizational level efforts to improve physician wellbeing and reduce turnover. Our objectives are: 1) to use a recent longitudinal data as a case example to examine the associations between physician self-reported burnout, intent to leave (ITL) and actual turnover within two years, and 2) to estimate the cost of physician turnover attributable to burnout.

Methods: We used de-identified data from 472 physicians who completed a quality improvement survey conducted in 2013 at two Stanford University affiliated hospitals to assess physician wellness. To maintain the confidentially of survey responders, potentially identifiable demographic variables were not used in this analysis. A third party custodian of the data compiled turnover data in 2015 using medical staff roster. We used logistic regression to adjust for potentially confounding factors.

Results: At baseline, 26\% of physicians reported experiencing burnout and 28\% reported ITL within the next 2 years. Two years later, $13 \%$ of surveyed physicians had actually left. Those who reported ITL were more than three times as likely to have left. Physicians who reported experiencing burnout were more than twice as likely to have left the institution within the two-year period (Relative Risk $(R R)=2.1 ; 95 \% \mathrm{Cl}=1.3-3.3$ ). After adjusting for surgical specialty, work hour categories, sleep-related impairment, anxiety, and depression in a logistic regression model, physicians who experienced burnout in 2013 had 168\% higher odds (Odds Ratio =2.68, 95\% Cl: 1.34-5.38) of leaving Stanford by 2015 compared to those who did not experience burnout. The estimated two-year recruitment cost incurred due to departure attributable to burnout was between $\$ 15,544,000$ and $\$ 55,506,000$. Risk of ITL attributable to burnout was 3.7 times risk of actual turnover attributable to burnout.
\end{abstract}

Conclusions: Institutions interested in the economic cost of turnover attributable to burnout can readily calculate this parameter using survey data linked to a subsequent indicator of departure from the institution. ITL data in cross-sectional studies can also be used with an adjustment factor to correct for overestimation of risk of intent to leave attributable to burnout.

Keywords: Burnout, Physician well-being, Turnover, Intent to leave

\footnotetext{
* Correspondence: trockel@stanford.edu

${ }^{1}$ Department of Psychiatry and Behavioral Sciences, Stanford University, 401

Quarry Road, Office 1320, Stanford, CA 94305, USA

${ }^{2}$ Stanford Medicine Well MD Center, Stanford University, Stanford, CA 94305, USA

Full list of author information is available at the end of the article
}

C The Author(s). 2018 Open Access This article is distributed under the terms of the Creative Commons Attribution 4.0 International License (http://creativecommons.org/licenses/by/4.0/), which permits unrestricted use, distribution, and reproduction in any medium, provided you give appropriate credit to the original author(s) and the source, provide a link to the Creative Commons license, and indicate if changes were made. The Creative Commons Public Domain Dedication waiver (http://creativecommons.org/publicdomain/zero/1.0/) applies to the data made available in this article, unless otherwise stated. 


\section{Background}

The increasing prevalence of burnout among physicians and its negative effects on health care quality are well documented [1, 2]. Prevention programs implemented at the organizational level are likely to be more effective in reducing physician burnout than programs that only target individual physicians (e.g. time management, stress reduction and resilience building skills) [3]. Accurate information on the economic cost of physician burnout to health care organizations may help motivate systematic organizational level efforts to improve physician wellbeing [4]. Medical errors, malpractice suits, physician turnover, reductions in clinical work hours, and lower patient satisfaction are some the consequences of physician burnout that result in increased organizational costs [4-7]. Many factors that have been identified as contributing factors to burnout- such as low professional satisfaction, medical-legal, health, and financial issues, lack of alignment between personal and organizational values and challenging practice arrangements [8-10] are also factors that contribute to physicians' turnover or early retirement $[1,11-13]$.

Although many reports have demonstrated associations between burnout and intent to leave, [7, 14-23] only one study has examined the association between physician burnout and actual subsequent turnover in an academic medical center in the US [6]. In terms of estimated cost of physician burnout, there is only one study that has estimated the cost of departure, based on intent to leave data, attributable to burnout in Canada in 2014 [17].

The current gold standard to assess burnout out is the Maslach Burnout Inventory-Human Services Survey (MBI-HSS), with 22 items measuring three common symptoms of burnout: emotional exhaustion, depersonalization, and lack of personal accomplishment. Another commonly used measure of burnout in physicians is a validated nonproprietary one-item self-reported burnout scale [24-27] which has a strong positive correlation with the emotional exhaustion sub-scale of the MBI [26, 27]. It is the emotional exhaustion subscale of MBI that has been shown to be the strongest predictor of physician attrition [6] and intent to leave the institution $[12,19,28]$. Burnout indicated by the one-item self-reported scale is also associated with physicians' intent to leave, $[15,23]$ while no associations have been found between depersonalization and physician attrition [6] or intent to leave [19, 28]. Emotional exhaustion correlates with anxiety and depression in physicians [29, 30]. Previous reports examining the effect of physician burnout on intent to leave and/or actual departure have not adjusted for the effects of anxiety and depression.

The primary objective of our study is to examine the associations of physician self-reported burnout with intent to leave and actual turnover, using a recent longitudinal data case example, both before and after adjusting for anxiety and depression. The second objective is to estimate the cost of physician turnover attributable to burnout. The third objective is to explore the relationship between intent to leave and actual turnover, and thus to assess the feasibility of using intent to leave data as a proxy for turnover data when data on actual turnover is not available.

\section{Methods}

Study design

Between April-May 2013, the Stanford Committee for Professional Satisfaction and Support (SCPSS) conducted a survey to assess wellness of physicians affiliated with Stanford University. The purpose of the 2013 Physician Wellness Survey was to help SCPSS develop, implement, and evaluate quality improvement projects and interventions to support physicians' professional fulfillment at Stanford and to prevent burnout [31]. We used de-identified data from this survey for this study. This analysis of de-identified data was deemed to be exempt (a non-human subject research study) by Stanford University's Institutional Review Board (IRB). Because we used a de-identified database, demographic data such as race, age, gender, clinical specialty (except for surgical vs. non-surgical specialty) and academic rank were not available and therefore not included in our analysis.

\section{Setting and participants}

Approximately $10 \%(n=249)$ of physicians credentialed at one or both of two Stanford affiliated hospitals were randomly selected from the medical staff and offered a \$25 gift certificate to complete the Physician Wellness Survey, of which 162 (65\% response rate) did so. In addition to the random sample, 669 (31\% response rate) of the remaining 2135 medical staff members from both hospitals completed the subsequent survey of all physicians. All medical staff - including both employed and non-employed (adjunct) faculty (2135) as well as community physicians (249) - were invited to participate in this survey $(2135+249=2384)$. The overall response rate for this survey was $34.9 \%([162+669] / 2384)$. Scores on survey measures from the two samples did not differ significantly. For this analysis, we included faculty physicians employed by Stanford University from both samples who consented to retention of their e-mail address, which enabled us to link their survey responses across time and to other data (Fig. 1, $n=472$ ).

The Physician Wellness Survey included previously developed and validated measures to assess self-reported burnout [25-27] and intent to leave [23, 32, 33]. We used the NIH Patient-Reported Outcomes Measurement Information System (PROMIS ${ }^{\circ}$ ) Short Forms to assess sleep-related impairment [34], depression, and anxiety 


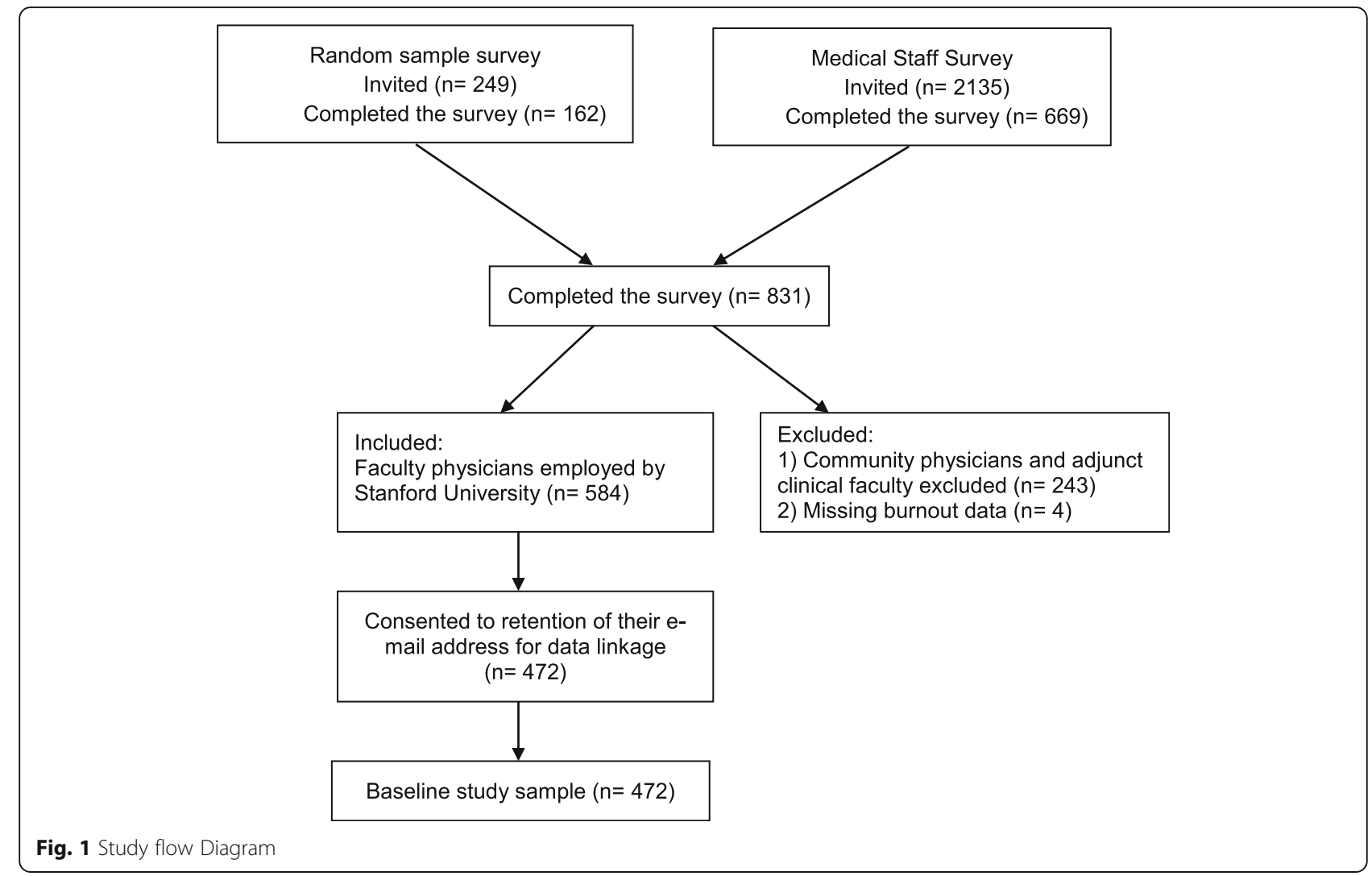

$[35,36]$. Sleep-related impairment scores range from a minimum of 8 to maximum of 40 , and anxiety and depression scores each range from 4 to 20 . The $\mathrm{NIH}$ PROMIS guidelines can be used to identify T-scores that correspond to raw scores of each scale. T-scores of 50 or higher (with a standard deviation of 10) in these instruments are more likely to represent people with poorer health than the general population [37-39]. Turnover data in 2015 was compiled by a third party custodian of the data using the medical staff directory. The cost of recruitment and start-up costs for new faculty hires was provided by the Stanford School of Medicine Chief Financial Officer.

\section{Statistical methods}

We analyzed data using IBM SPSS Statistics 23 (IBM Corp, Armonk, NY, USA). All reported $p$-values are 2-tailed, with statistical significance set at $p<0.05$. We calculated relative risk (RR) ratio for unadjusted relationships between burnout and turnover, between burnout and intent to leave, and between intent to leave and turnover. We used logistic regression to estimate odds ratio (OR) effects adjusted for potentially confounding variables including hours worked per week category, $[1$, $40,41]$ surgical specialty (yes, no), [20, 42] and sleep-related impairment, anxiety and depression scales (continuous variables) [43].

\section{Results}

Our baseline study sample includes 472 physicians (Fig. 1). Sixty-one (13\%) physicians in the baseline sample in 2013 had left Stanford by 2015. As baseline $26 \%$ of physician reported experiencing burnout and 133 (28\%) reported intent to leave within the next 2 years (Table 1). The majority of physicians in our sample reported working over $50 \mathrm{~h}$ per week. Based on the PROMIS guidelines, the closest T-scores and standard errors corresponding to the raw score of sleep-related impairment falls between $50.3 \pm 2.7$ and $51.6 \pm 2.6$, [37] for anxiety falls between $48.0 \pm 3.6$ and $51.2 \pm 3.1$, [38] and for depression falls between 49.0 \pm 3.2 and $51.8 \pm 2.7[37,39]$.

\section{Burnout and turnover}

The associations between burnout and turnover are reported in Table 2. After adjusting for surgical specialty, work hour categories, sleep-related impairment, anxiety, and depression, physicians who experienced burnout in 2013 had 168\% higher odds (Odds Ratio $(\mathrm{OR})=2.68$, 95\% CI: 1.34-5.38, Table 2) of leaving Stanford by 2015 compared to those who did not experience burnout. Surgical specialty, work hours category, sleep-related impairment, anxiety and depression were not statistically significant predictors of physician turnover. 
Table 1 Characteristics of physicians in the baseline study sample, and associations between physician attrition and burnout

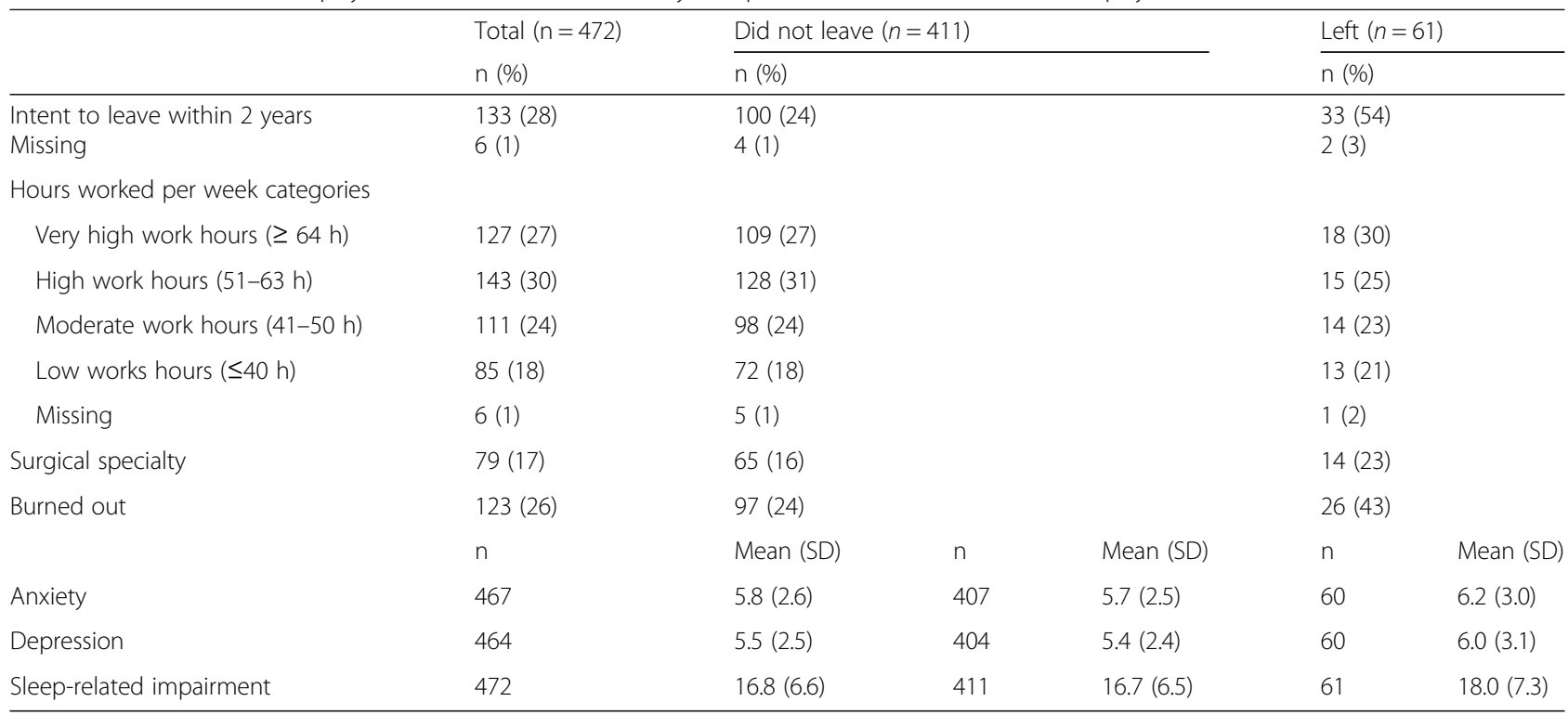

Abbreviations: $n$ number, SD Standard Deviation

\section{Estimating the economic cost of burnout}

Twenty one percent of physicians who reported one or more symptoms of burnout in 2013 had left by 2015 compared with only $10 \%$ of those without burnout symptoms in 2013 (Fig. 2, $\mathrm{RR}=2.1$; 95\% C: 1.3-3.3). Therefore, departure of $11 \%$ of those who were burned out 2 years earlier may be attributed to burnout [attributable risk $=21-$ $10 \%=11 \%$. The overall rate of burnout in 2013 was $26 \%$. If these results generalize to all physicians currently employed by the Stanford School of Medicine $(n=2023$ out of 2678 total medical staff - 655 are community physicians and/or adjunct clinical faculty members not employed by the School of Medicine), then over the next 2 years the departure of 58 faculty physicians will be attributable to burnout $[0.11 * 0.26 * 2023=58]$. The cost of physician recruitment and start-up (not including housing) at this AMC ranges between $\$ 268,000$ - $\$ 957,000$ per physician based on specialty, experience and expertise. Therefore, the minimum estimated two-year economic

Table 2 Association between physician turnover and burnout

\begin{tabular}{lll}
\hline & OR $(95 \% \mathrm{Cl})$ & $p$-value \\
\hline Unadjusted Model & $2.40(1.38-4.19)$ & 0.002 \\
Adjusted Model 1 $^{\mathrm{a}}$ & $2.41(1.38-4.21)$ & 0.002 \\
Adjusted Model 2 $^{\mathrm{b}}$ & $2.82(1.56-5.10)$ & 0.001 \\
Adjusted Model 3 $^{\mathrm{c}}$ & $2.77(1.47-5.25)$ & 0.002 \\
Adjusted Model 4 $^{\mathrm{d}}$ & $2.68(1.34-5.38)$ & 0.005
\end{tabular}

Abbreviations: OR Odds Ratio, $\mathrm{Cl}$ Confidence Interval

${ }^{a}$ Adjusted for Surgical Specialty

${ }^{b}$ Adjusted for Surgical Specialty, Hours Worked per Week Category

c Adjusted for Surgical Specialty, Hours Worked per Week Category, and

Sleep-Related Impairment

${ }^{\mathrm{d}}$ Adjusted for Surgical Specialty, Hours Worked per Week Category, Sleep-

Related Impairment, Anxiety, and Depression loss due to physician departure attributable to burnout will range between $\$ 15,544,000\left(58^{*} \$ 268,000\right)$ and $\$ 55,506,000$ (58* $\$ 957,000)$.

\section{Intent to leave versus actual turnover}

In 2013, 133 (28\%) of physicians indicated intent to leave their current practice within 2 years. Two years later, in 2015, 33 physicians out of 133 with intent to leave (24.8\%) had left Stanford compared to 26 physicians who left out of 333 without intent to leave (7.8\%) (Relative Risk (RR) = 3.2, 95\% CI: 2.0-5.1). Overall, 61 of the 472 physicians (13\%) who completed the 2013 survey had left Stanford by 2015.

\section{Burnout and intent to leave}

In the fully adjusted model (Table 3 ), those who were experiencing burnout had 4.86 times higher odds of intent to leave compare to those who were not experiencing burnout. We also found that for every one point (range: 4-20) increase in depression score, physicians had $22 \%$ greater odds of intent to leave (Table 4 ). There were no statically significant associations between intent to leave and surgical specialty, work hour category, sleep-related impairment or anxiety scores (Table 4).

Among physicians who reported one or more symptoms of burnout in 2013, 58.7\% indicated intent to leave their practice within 2 years, compared with only $18 \%$ of those without burnout symptoms $(\mathrm{RR}=3.3$; 95\% C:2.54.3). Therefore, intent to leave of $41 \%$ of those who were burned out may be attributed to burnout [attributable risk $=58.7-18 \%=40.7 \%$ ] which is about 3.7 times higher than the actual observed rate of subsequent turnover attributable to burnout. 


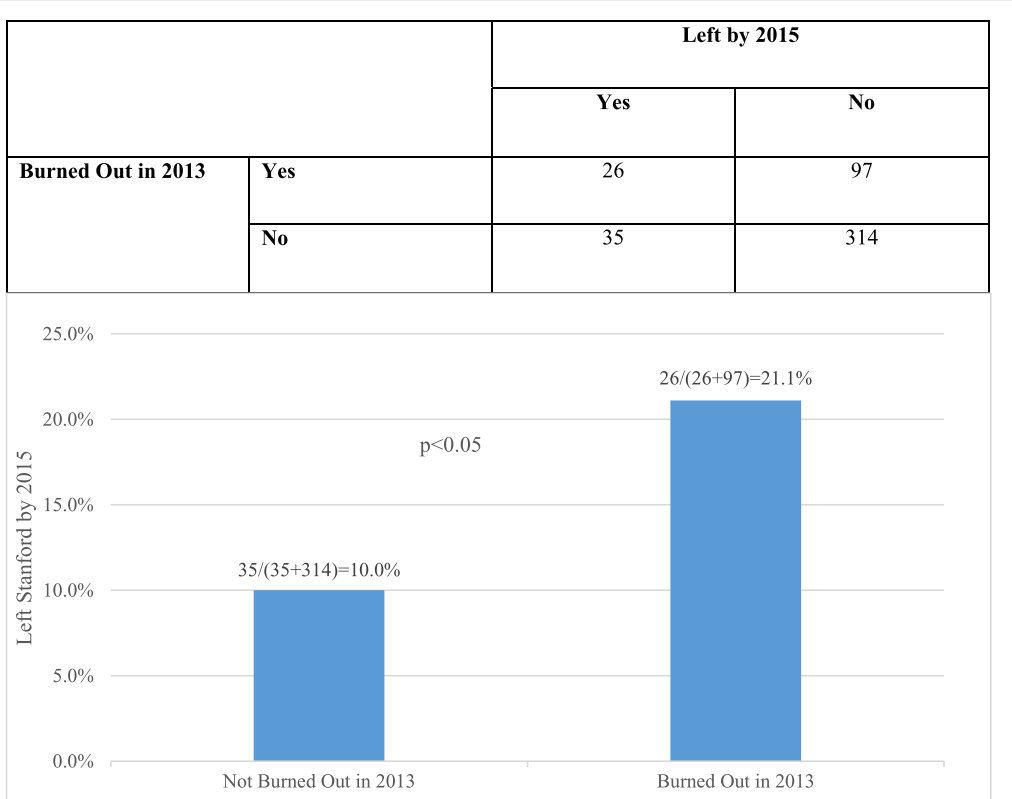

Fig. 2 Physician attrition and burnout. Attributable risk of burnout $=21-10 \%=11 \%$. Attrition of $11 \%$ of those who were burned out may be attributed to burnout, while attrition of 10\% may be attributed to other causes, such as a compelling career opportunity elsewhere, or planned retirement

\section{Discussion}

The results of our analysis indicate that 1) physicians who are experiencing burnout are more than twice likely to leave their practice, and that the effect of burnout on turnover is independent of personal factors such as anxiety or depression; 2) the economic cost of turnover attributable to physician burnout is high, and; 3) intent to leave is a strong predictor of actual departure. Those who reported intent to leave the institution were more than three times as likely to leave within 2 years, compared to those who did not report intent to leave.

In this study sample, physicians had modestly higher scores for sleep-related impairment, and similar to median scores for anxiety, and depression to median scores from PROMIS reference populations (the 2000 General US Census and a clinical sample for sleep-related impairment,

Table 3 Association between physicians' intent to leave and burnout

\begin{tabular}{lll}
\hline & OR $(95 \% \mathrm{Cl})$ & $p$-Value \\
\hline Unadjusted Model & $6.48(4.11-10.21)$ & $<0.001$ \\
Adjusted Model 1 $^{\mathrm{a}}$ & $6.48(4.11-10.20)$ & $<0.001$ \\
Adjusted Model 2 $^{\mathrm{b}}$ & $7.06(4.38-1.40)$ & $<0.001$ \\
Adjusted Model 3c $^{c}$ & $6.63(3.98-11.03)$ & $<0.001$ \\
Adjusted Model 4 $^{\mathrm{d}}$ & $4.86(2.81-8.39)$ & $<0.001$ \\
\hline
\end{tabular}

Abbreviations: OR Odds Ratio, Cl Confidence Interval

${ }^{a}$ Adjusted for Surgical Specialty

${ }^{b}$ Adjusted for Surgical Specialty, Hours Worked per Week Category

c Adjusted for Surgical Specialty, Hours Worked per Week Category, and

Sleep-Related Impairment

${ }^{\mathrm{d}}$ Adjusted for Surgical Specialty, Hours Worked per Week Category, Sleep-

Related Impairment, Anxiety, and Depression and the 2000 General US Census for anxiety and depression) [37-39]. Although depression was a significant predictor of intent to leave even after adjusting for other variables, only burnout (an indicator of work-specific distress), rather than depression and anxiety (indicators of general distress) was a significant predictor of actual physician turnover. Similar to other studies, [40, 44] our results suggest that intent to leave is a strong predictor of physician turnover. In our baseline sample, $28 \%$ reported intent to leave the institution within 2 years, and after 2 years $13 \%$ of physicians had left Stanford. Those who reported intent to leave in 2013 were more than three times as likely to have left by 2015 . Intent to leave may be a valid proxy indicator of turnover to calculate organization-specific financial burden of physician turnover attributable to

Table 4 Association between intent to leave and burnout details of Model 4

\begin{tabular}{llll}
\hline & OR & $(95 \% \mathrm{Cl})$ & $p$-Value \\
\hline Burned Out & 4.86 & $2.81-8.39$ & $<0.001$ \\
Surgical Specialty & 1.39 & $0.75-2.57$ & 0.29 \\
Very High Work Hours & 0.51 & $0.25-1.05$ & 0.07 \\
High Work Hours & 0.60 & $0.30-1.20$ & 0.15 \\
Moderate Work Hours & 0.75 & $0.37-1.51$ & 0.42 \\
Low Work Hours (reference group) & 1 & - & - \\
Sleep-Related Impairment & 0.99 & $0.95-1.03$ & 0.63 \\
Anxiety & 1.01 & $0.89-1.16$ & 0.85 \\
Depression & 1.22 & $1.06-1.39$ & 0.004 \\
\hline
\end{tabular}

Abbreviations: OR Odds Ratio, Cl Confidence Interval 
burnout, when data on actual turnover is not available. However, intent to leave attributable to burnout is much higher than actual subsequent turnover attributable to burnout. An adjustment factor for this difference will improve accuracy when estimating financial burden from intent to leave data where turnover data is not yet available. The adjustment factor indicated by the present study is to divide intent to leave attributable to burnout by 3.7 to estimate actual subsequent turnover attributable to burnout. Additional data from a heterogeneous set of health care organizations will help clarify the variance in difference between intent to leave versus actual subsequent turnover attributable to burnout.

Future investigation from a heterogeneous set of health care organizations will also help clarify the variance in economic cost of physician turnover attributable to burnout. Physicians working in academic medical centers often have unique challenges (e.g. academic productivity expectations) and benefits (e.g. opportunities to teach and conduct research) that may affect the relationship between burnout and turnover. The only other published data-to our knowledge-on the association between burnout and turnover indicates an effect of burnout on physician turnover similar in magnitude [6] to the present study finding, which provides some across-organization validity. However, this collaborating data is also from an AMC, whereas most health care organizations in the United States are not AMCs. It is not clear that these findings will generalize accurately in attempts to estimate cost of turnover attributable to burnout in non-AMC organizations. The only published article to date [4] that attempts to use turnover attributable to burnout to build an economic argument for investing in physician well-being relies on unpublished data from the present study [45-47].

The present study is limited to observation of the relationship between burnout and subsequent turnover, which provides necessary but far from sufficient evidence of a causal relationship. In addition to an AMC focus, the present study is also limited to secondary data analysis of completely de-identified evaluation data, without demographic data that might be helpful in assessing generalizability of results. With these limitations in mind, the findings of the present study, coupled with previous evidence of effective strategies to mitigate burnout, [48] suggest feasibility of longitudinal study to determine the effect of interventions to mitigate burnout on cost of physician turnover.

Average turnover rates observed at Stanford (13\% in 2 years) are similar to national averages. The Cejka Search and American Medical Group Association Physician Retention Survey results show that the annual rate of physician turnover was about $6 \%$ in 2010 and 2011 [49]. If interventions can reduce burnout to half of the current rate, Stanford Medicine may be able to save $\$ 7,772,000$ to $\$ 27,753,000$ in physician recruitment costs alone during the subsequent 2 years. These figures based on recruitment cost at Stanford, which are comparable to national averages reported elsewhere $[4,50]$.

Our estimate of the high cost of turnover attributable to burnout does not include either the loss of revenue due to physician faculty position vacancy or the diminished economic productivity associated with burnout among those who remain employed-such as a reduction in work-hours [51]. Nor does this estimate include a broader range of costs associated with burnout, such as the disruption in the quality and continuity of direct patient care or the reduced health of physicians $[9,52]$. Investment in interventions to reduce burnout may pay dividends in all of these domains.

\section{Conclusion}

Our results suggest that the economic cost of physician faculty attrition attributable to burnout is high. This finding may help motivate further investigation to determine the effect of strategies to mitigate burnout on physician turnover and associated economic burden. Academic medical centers offer physicians rewarding careers, including opportunities to develop new frontiers in patient care, create and advance new knowledge, and to educate and mentor trainees. In turn, these institutions benefit immensely from talented physicians who drive high standards in patient care, research, and education. Investing in strategies that prevent or reduce burnout may render economic benefits associated with reduced physician attrition. Perhaps more compelling for AMC-employed physicians and the patients they serve are the benefits that reduced burnout may render to physicians' personal and professional wellbeing and to the quality of clinical care.

\footnotetext{
Acknowledgements

We would like to thank Marcia Cohen, the Senior Associate Dean for Finance and Administration for the School of Medicine at Stanford University, for providing us the cost estimates of physician recruitment at Stanford. We would also like to express our gratitude to Véronique Grenon, FCAS and Ming Lu at the Risk Authority Stanford for data management, linking and de-identification of the data set.

\section{Funding}

None

Availability of data and materials

The data that support the findings of this study are property of The Risk Authority Stanford and Stanford Medicine WellMD Center strict restrictions apply to the availability of these data, which were used under license and intuitional privacy and confidentiality rules for the current study, and so are not publicly available. Completely deidentified data are however available for the purpose of interpretation, replication and building upon the findings reported in this article from the corresponding author upon reasonable request and with permission of The Risk Authority Stanford and Stanford Medicine WellMD Center.
} 


\section{Authors' contributions}

MT and MSH had full access to de-identified study data and performed statistical analyses. MT led the design and conduct of the study; extraction, management, analysis, interpretation of the data; writing the manuscript; and takes responsibility for the integrity of the data and the accuracy of the data analysis and interpretation as the corresponding author. MSH was involved in the analysis, interpretation of the data, and writing the manuscript. BB made significant contributions to the final manuscript. PVD suggested the business case idea. All authors were involved in conduct of this study, interpretation of the results, critical reviewing and editing the manuscript, and the final approval for submission. All authors had authority over manuscript preparation and decisions to submit the manuscript for publication, and take full responsibility for the accuracy of the data presented in this manuscript.

\section{Ethics approval and consent to participate}

This analysis of de-identified data was deemed exempt by Stanford University's Human Subjects Research Institutional Review Board (IRB).

\section{Consent for publication}

Not applicable.

\section{Competing interests}

The authors declare that they have no competing interests.

\section{Publisher's Note}

Springer Nature remains neutral with regard to jurisdictional claims in published maps and institutional affiliations.

\section{Author details}

'Department of Psychiatry and Behavioral Sciences, Stanford University, 401 Quarry Road, Office 1320, Stanford, CA 94305, USA. ${ }^{2}$ Stanford Medicine Well MD Center, Stanford University, Stanford, CA 94305, USA. ${ }^{3}$ Stanford Health Care, 300 Pasteur Dr, Stanford, CA 94305, USA. ${ }^{4}$ Stanford Children's Health | Lucile Packard Children's Hospital, Pediatric Rheumatology, 730 Welch Rd, Palo Alto, CA 94304, USA. ${ }^{5}$ Stanford Emergency Department, 300 Pasteur Dr, Palo Alto, CA 94304, USA. ${ }^{6}$ Stanford Children's Health | Lucile Packard Children's Hospital, 725 Welch Rd, Palo Alto, CA 94304, USA. ${ }^{7}$ The Risk Authority Stanford, 1510 Page Mill Road, Palo Alto, CA 94304, USA.

Received: 31 March 2018 Accepted: 30 October 2018 Published online: 27 November 2018

\section{References}

1. Shanafelt TD, Hasan O, Dyrbye LN, Sinsky C, Satele D, Sloan J, West CP. Changes in burnout and satisfaction with work-life balance in physicians and the general US working population between 2011 and 2014. Mayo Clin Proc. 2015;90:1600-13.

2. Dewa CS, Loong D, Bonato S, Trojanowski L. The relationship between physician burnout and quality of healthcare in terms of safety and acceptability: a systematic review. BMJ Open. 2017;7:e015141.

3. Panagioti M, Panagopoulou E, Bower P, Lewith G, Kontopantelis E, ChewGraham C, Dawson S, van Marwijk H, Geraghty K, Esmail A. Controlled interventions to reduce burnout in physicians: a systematic review and meta-analysis. JAMA Intern Med. 2017;177:195-205.

4. Shanafelt T, Goh J, Sinsky C. The business case for investing in physician well-being. JAMA Intern Med. 2017;177:1826-32.

5. Dyrbye $L N$, Trockel M, Frank E, et al. DEvelopment of a research agenda to identify evidence-based strategies to improve physician wellness and reduce burnout. Ann Intern Med. 2017;166:743-4.

6. Windover AK, Martinez K, Mercer MB, Neuendorf K, Boissy A, Rothberg MB. Correlates and outcomes of physician burnout within a large Academic Medical Center. JAMA Intern Med. 2018.

7. Dewa CS, Loong D, Bonato S, Thanh NX, Jacobs P. How does burnout affect physician productivity? A systematic literature review. BMC Health Serv Res. 2014;14:325.

8. Edwards N, Kornacki MJ, Silversin J. Unhappy doctors: what are the causes and what can be done? BMJ. 2002;324:835.

9. Misra-Hebert AD, Kay R, Stoller JK. A review of physician turnover: rates, causes, and consequences. Am J Med Qual. 2004;19:56-66.

10. Williams ES, Konrad TR, Scheckler WE, Pathman DE, Linzer M, McMurray JE, Gerrity M, Schwartz M. Understanding physicians' intentions to withdraw from practice: the role of job satisfaction, job stress, mental and physical health. Health Care Manag Rev. 2010;35:105-15.

11. Silver MP, Hamilton AD, Biswas A, Warrick NI. A systematic review of physician retirement planning. Hum Resour Health. 2016;14:67.

12. Pantenburg B, Luppa M, Konig HH, Riedel-Heller SG. Burnout among young physicians and its association with physicians' wishes to leave: results of a survey in Saxony, Germany. J Occup Med Toxicol. 2016;11:2.

13. Shanafelt TD, Mungo M, Schmitgen J, Storz KA, Reeves D, Hayes SN, Sloan JA, Swensen SJ, Buskirk SJ. Longitudinal study evaluating the association between physician burnout and changes in professional work effort. Mayo Clin Proc. 2016;91:422-31.

14. Sinsky CA, Dyrbye LN, West CP, Satele D, Tutty M, Shanafelt TD. Professional satisfaction and the career plans of US physicians. Mayo Clin Proc. 2017;92: $1625-35$.

15. Rabatin J, Williams E, Baier Manwell L, Schwartz MD, Brown RL, Linzer M. Predictors and outcomes of burnout in primary care physicians. J Prim Care Community Health. 2016;7:41-3.

16. Shanafelt TD, Raymond M, Kosty M, Satele D, Horn L, Pippen J, Chu Q, Chew H, Clark WB, Hanley AE, et al. Satisfaction with work-life balance and the career and retirement plans of US oncologists. J Clin Oncol. 2014;32: $1127-35$.

17. Dewa CS, Jacobs $P$, Thanh NX, Loong D. An estimate of the cost of burnout on early retirement and reduction in clinical hours of practicing physicians in Canada. BMC Health Serv Res. 2014;14:254.

18. Estryn-Behar M, Fry C, Guetarni K, Aune I, Machet G, Doppia MA, Lassauniere JM, Muster D, Pelloux P, Prudhomme C. Work week duration, work-family balance and difficulties encountered by female and male physicians: results from the French SESMAT study. Work. 2011:40(Suppl 1):S83-100.

19. Zhang $Y$, Feng $X$. The relationship between job satisfaction, burnout, and turnover intention among physicians from urban state-owned medical institutions in Hubei, China: a cross-sectional study. BMC Health Serv Res. 2011:11:235.

20. Shanafelt T, Sloan J, Satele D, Balch C. Why do surgeons consider leaving practice? J Am Coll Surg. 2011;212:421-2.

21. Fuss I, Nubling M, Hasselhorn HM, Schwappach D, Rieger MA. Working conditions and work-family conflict in German hospital physicians: psychosocial and organisational predictors and consequences. BMC Public Health. 2008;8:353.

22. Goldberg R, Boss RW, Chan L, Goldberg J, Mallon WK, Moradzadeh D, Goodman EA, McConkie ML. Burnout and its correlates in emergency physicians: four years' experience with a wellness booth. Acad Emerg Med. 1996;3:1156-64.

23. Schmoldt RA, Freeborn DK, Klevit HD. Physician burnout: recommendations for HMO managers. HMO Pract. 1994;8:58-63.

24. Mini Z burnout survey [https://www.stepsforward.org/modules/physicianburnout-survey].

25. Dolan ED, Mohr D, Lempa M, Joos S, Fihn SD, Nelson KM, Helfrich CD. Using a single item to measure burnout in primary care staff: a psychometric evaluation. J Gen Intern Med. 2015;30:582-7.

26. Hansen V, Girgis A. Can a single question effectively screen for burnout in Australian cancer care workers? BMC Health Serv Res. 2010;10:341.

27. Rohland BM, Kruse GR, Rohrer JE. Validation of a single-item measure of burnout against the Maslach burnout inventory among physicians. Stress Health. 2004;20:75-9.

28. Grunfeld E, Whelan TJ, Zitzelsberger L, Willan AR, Montesanto B, Evans WK. Cancer care workers in Ontario: prevalence of burnout, job stress and job satisfaction. Can Med Assoc J. 2000;163:166-9.

29. Trockel M, Bohman B, Lesure E, Hamidi MS, Welle D, Roberts L, Shanafelt T. A brief instrument to assess both burnout and professional fulfillment in physicians: reliability and validity, including correlation with self-reported medical errors, in a sample of resident and practicing physicians. Acad Psychiatry. 2018:42:11-24.

30. Lemaire JB, Wallace JE. How physicians identify with predetermined personalities and links to perceived performance and wellness outcomes: a cross-sectional study. BMC Health Serv Res. 2014;14.

31. The 2013 Stanford Physician Wellness Survey [https://wellmd.stanford.edu/ center $1 /$ survey.html].

32. Freeborn DK. Satisfaction, commitment, and psychological well-being among HMO physicians. West J Med. 2001;174:13-8. 
33. McMurray JE, Linzer M, Konrad TR, Douglas J, Shugerman R, Nelson K. The work lives of women physicians results from the physician work life study. The SGIM career satisfaction study group. J Gen Intern Med. 2000;15:372-80.

34. Buysse DJ, Yu L, Moul DE, Germain A, Stover A, Dodds NE, Johnston KL, Shablesky-Cade MA, Pilkonis PA. Development and validation of patientreported outcome measures for sleep disturbance and sleep-related impairments. Sleep. 2010;33:781-92.

35. Pilkonis PA, Choi SW, Reise SP, Stover AM, Riley WT, Cella D. Item banks for measuring emotional distress from the patient-reported outcomes measurement information system (PROMIS(R)): depression, anxiety, and anger. Assessment. 2011;18:263-83.

36. Riley WT, Pilkonis P, Cella D. Application of the National Institutes of Health patient-reported outcome measurement information system (PROMIS) to mental health research. J Ment Health Policy Econ. 2011;14:201-8.

37. A brief guide to the Patient-Reported Outcomes Measurement Information System (PROMIS) Sleep-Related Impairment instruments [https://www. assessmentcenter.net/documents/PROMIS\%20SleepRelated\%20lmpairment\%20Scoring\%20Manual.pdf].

38. A brief guide to the Patient-Reported Outcomes Measurement Information System (PROMIS) Anxiety instruments [https:/wwww.assessmentcenter.net/ documents/PROMIS\%20Anxiety\%20Scoring\%20Manual.pdf].

39. A brief guide to the Patient-Reported Outcomes Measurement Information System (PROMIS) Depression instruments [https://www.assessmentcenter. net/documents/PROMIS\%20Depression\%20Scoring\%20Manual.pdf].

40. Joyce CM, Wang WC, McDonald HM. Retirement patterns of Australian doctors aged 65 years and older. Aust Health Rev. 2015;39:582-7.

41. Degen C, Li J, Angerer P. Physicians' intention to leave direct patient care: an integrative review. Hum Resour Health. 2015;13:74.

42. Wai PY, Dandar V, Radosevich DM, Brubaker L, Kuo PC. Engagement, workplace satisfaction, and retention of surgical specialists in academic medicine in the United States. J Am Coll Surg. 2014;219:31-42.

43. Trockel M, Bohman B, Lesure S, Hamidi M, Welle D, Roberts L, Shanafelt T. A dynamic instrument to assess both burnout and professional fulfillment in physicians: reliability and validity including correlation with self-reported medical errors; 2017.

44. Corrice A, Fox S, Bunton S. Retention of full-time clinical M.D. faculty at U.S. medical schools. Analysis in Brief-Association of American Medical Colleges (AAMC). 2011;11:1-2.

45. Berg S. At Stanford, physician burnout costs at least $\$ 7.75$ million a year. In AMA Wire, vol. https://wire.ama-assn.org/life-career/stanford-physicianburnout-costs-least-775-million-year; 2017.

46. Schrijver I, Brady KJ, Trockel M. An exploration of key issues and potential solutions that impact physician wellbeing and professional fulfillment at an academic center. PeerJ. 2016;4:e1783.

47. Hamidi MS, Bohman B, Sandborg C, Smith-Coggins R, de Vries P, Albert MS, Murphy ML, Welle D, Trockel MT. The economic cost of physician turnover attributable to burnout. In 2017 American Conference on Physician Health (ACPH) Abstract Book. San Francisco: Efficiency of Practice. 2017. p. 35. https://med.stanford.edu/content/dam/sm/CME/documents/brochures/ 2017/ACPH-Abstract-Book-FULL.pdf.

48. West CP, Dyrbye LN, Erwin PJ, Shanafelt TD. Interventions to prevent and reduce physician burnout: a systematic review and meta-analysis. Lancet. 2016;388:2272-81

49. Schutte L. Understanding the real costs of recruiting and retaining physicians. Recruiting Physicians Toaday (RPT). 2012;20:1-3.

50. Schutte L. Building a Business Case for Recruitment and Retention Best Practice. In: Journal of Association of Staff Physician Recruiters (ASPR). St. Louis: Association of Staff Physician Recruiters; 2012. https://www.aspr.org/ page/696.

51. Shanafelt TD, Dyrbye LN, West CP, Sinsky CA. Potential impact of burnout on the US physician workforce. Mayo Clin Proc. 2016:91:1667-8.

52. Wallace JE, Lemaire J. Physician well being and quality of patient care: an exploratory study of the missing link. Psychol Health Med. 2009;14:545-52.

\section{Ready to submit your research? Choose BMC and benefit from:}

- fast, convenient online submission

- thorough peer review by experienced researchers in your field

- rapid publication on acceptance

- support for research data, including large and complex data types

- gold Open Access which fosters wider collaboration and increased citations

- maximum visibility for your research: over $100 \mathrm{M}$ website views per year

At BMC, research is always in progress.

Learn more biomedcentral.com/submissions 